A major purpose of the lechnical Information Center is to provide the broadest dissemination possible of information contained in DOE's Research and Development Reports to business industry, the academir communi. and federal, state and local governments.

Although a small portion of this report is not reproducible, it is being made available to expedite the availability of information on the research discussed herein.

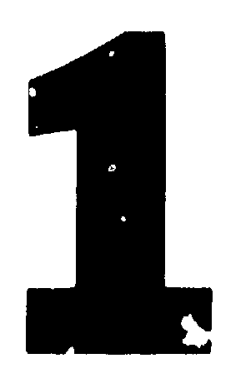


TITLE: TEN YEARS OF VELA X-RAY OBSERVATIONS

AUTHOR(S): $3 \Lambda \rightleftharpoons$ TERRELL and WILLIAM C. PRIEDHORSKY

SUBMITTED TO: SIMMER WORSHOP IN ASTRONOMY \& ASTROPHYSICS AT LICK OBSERVATORY SANTA CRUZ, CAIIFORNIA

\section{DISY 'I.AIMKR}

\section{Matice}

t hat been roproduced irom tho best ivallable copy to permit irom the best rosslble avallabillty.
Thix report was prepared us un account of work sponmored hy an esoncy of the United beates Ciovernment. Neither the United Siatex (iovernment nor any agenev thereof, nor any of their employees. mukes any warranty, expresu or implied, of auumes any legal liabillty or reaponatbility for the accuracy. trompletenems, or usefulnesa of uny information, apparalus, product, or process dimelomed, of represents that its use wisuld not infringe ivately ownod rights. Rofor. ence hefelin in any apecifíc commercial product, procesa, ur norvice by irade name, iredemart.

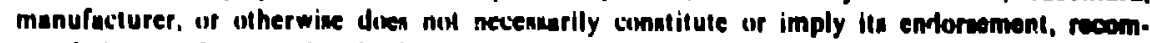
mendation. or favin ing hy the Ilnilesl Silnten fiugernment or any aponcy theroof. The viome and coptions of nuthors expresued hernin do nor necenuarily state of roflect thos of the Uniled Simlen Chuvernment or any naency thereul.

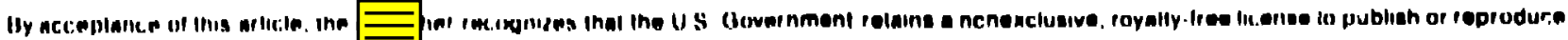

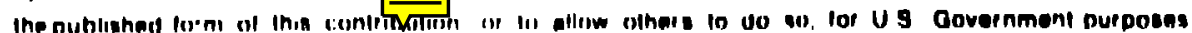


ABSTRACT: The Vela spacecraft, particularly Vela 5B, produced allsky $X$-ray data of unprecedented length and completeness. The data led to the discovery of $\mathrm{K}-\mathrm{ray}$ bursts and numerous transient or tbursts. Recent re-analysis has pat the data in the form of 10-ray skymaps covering a 7-year perlod, which have led to the discovery or confirmation of a number of long-term periodicities, and have made possible a time-lapse movie of the $X-r a y$ sky.

One spacecraft, Vela 5B, monltored the X-ray sky for more than 10 years, profucing all-sky data for a perlod of unprecedented length. The Vela spacecraft, watching for nuclear tests in space, were among the firat to be capable of $x$-ray astronomy. 1 vela $5 B$ observed the sky with collimated NaI photomultiplier detectors, sens1t1ve to $3-12 \mathrm{keV}$ X-rays, from 26 May 1969 to 19 June 1979. The detectors scannet along a great circle at right angles to the earthspacecraft axis as the spacecraft spun with a nominal perlod of 64 seconds. The very large orbttal radlus of $118000 \mathrm{~km}$ corresponds to an orbital perlod of 112. hours, so that the entire sky was observed In 55 hours, half of the orbltal perlod. Although the detectors had a sensitive area of only $27 \mathrm{~cm}^{2}$, they were quite adequate for observations of many $X-r a y$ burets, $2,3^{\prime}$ a few gamina-ray bursts ${ }^{4}$ and numerous transients.

The first and brightest of these transient sources was cen $x-4$, first observed-as an $X$-ray burst history, seen in Fig. 1, shows that it rose very rapidly to an Intensity considerably brighter than that of Sco $x-1$ and remalned bright for about 3 inonthil (each Ve:a count corresponds to $\sim 4 \times 10^{-18}$ erk8/ $\mathrm{cm}^{2}$, and to $\sim 25$ Uhuru counte). Cen $X-4$ then vanished for 10 years, not reappearing until May 1979, at which time it was poselble to Identify it opilcaliy. The rosition $\left(l=332.24^{\circ}, b=23.88^{\circ}\right)$ agreed well with tha: calculated ${ }^{7}$ for the carlier outburst.

The entire set of Vela data has been reprocessed in the last few years, with recallbration of viewing angle and correction of oome earliar problems in spacecraft data and in analyols. One of the reaulta has been a set of 10-day akymape for the 7-year pertod durlng which data acquialtion was most complete (4ay 1969-June 1976). These have recently bean put into the forn of a movie lin color , showing in ilme-lapee fauliton the changes in the $X-r a y$ sky map as seen by Vela 5H. Several examplea or these skymape have beon published.4,9, I0 Flyure 2 show the galactlc center portion of the 1969 skymap, with Cen $X-4$ prominent near sio $X-1$, normally the brlghtest wource. These akymaps repreaent the average count Ing rate above background in each $2^{\circ} \times 2^{\circ}$ area of the aky, by means of aymbols of varylng intensity (and color, in the movie). liach point mource li eprend over an nppreciable nren of the nkymap becauae of tho $6.1^{\circ} \times 6.1^{\circ}$ renolution 


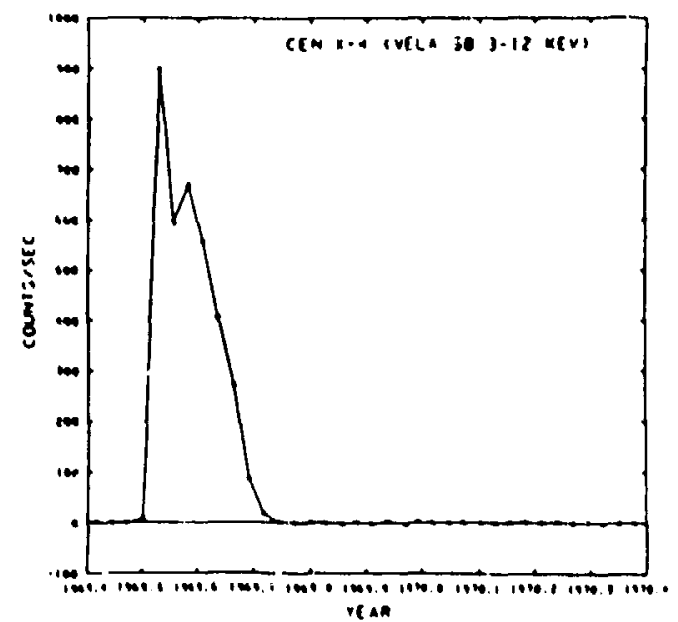

F18. 1. Time history of the 1969 Cen $x-4$ transient outburst.

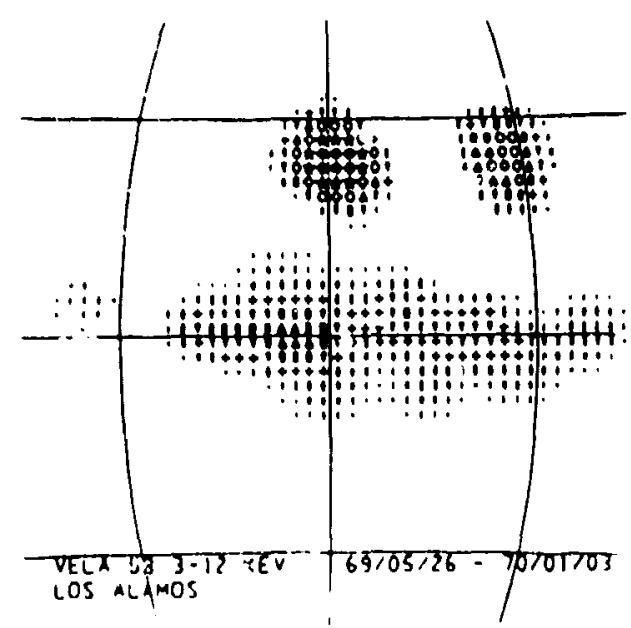

F18. 2. Galact1c center portion of the 1963 Vela 58 X-ray skumap.

(FWHM) of the collimator. An additional angular spread is introduced by the 1-second time resolution of the data.

Many sources, such as Cen $X-4$, are well-separated from others, and $1 t$ is not difficilt to evaluate the rime history and accurate position of such sources from these skymaps. In other cases it is necessary to use a least-souare fitting procedure $t=$ separate the data from sources which are only a few degrees apart. Such techniques have already resulted in long-term time his. iries of a number of $x$-ray sources.li-i3 In $A$ number of cagns new perlodictites have been found, such as the 294-day perlod of Cyg $X .1$ and the 132.5 -day perlod 13 of $6 \times 304-1$. In other cases previously suggested perlodiclties, wuch as the $111-1$ ay period 2 of $A 0535+26$ and the 41.5-day period ${ }^{3}$ of $6 \times 301-2$ have been confirmed, arid other perlods have been ruled out. A llumber of prevlously unknown transient outbirsta have been found in the Vela data. There was, for example, a bright transient outburat 13 froin 4U1145-61 in Apr11 1973, at a time when other spacecraft with oll-aky $X-r a y$ capability were not functioning.

An even more Interesting transient outourst occurred in June ¿973 from a previously unknown nource in Camelopardus?, v0332+53, whlch was also observed only by $V=1$ a $5 B$. T'hls source, an may be seen In Figure 3, rose gradually to an Intenalty of 1.4 Crah and chen died away, lasting for a total of 3 months. The slow rise in quite different from the more typical outburat of Cen $X-4$, seen in Fig. 1 . Tha position of this new sowre, nt kH1uctc coordirates $146.1^{\circ}$, $-2.0^{\circ}$, 19 known to an uncertainty of $0.0 .2^{\circ}$, and 1 a otill heing refined. This hard $X$-ray source gave cjear Indlcationa of rapid fluctuations on a wo:t time scale, which are under inveatigntion.

A number of extragalactic cources are almo quite evident in the Vela data. One of the most interenting of thene la the neareat acclve galaxy, Cen A (NCC 5128). Durling the pertod 1973-197; the

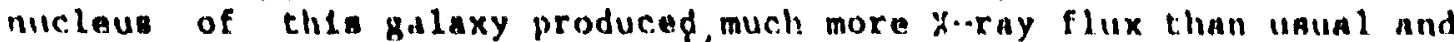

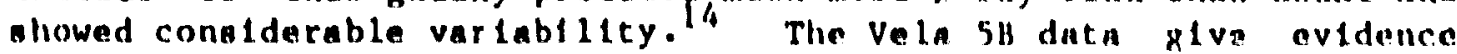




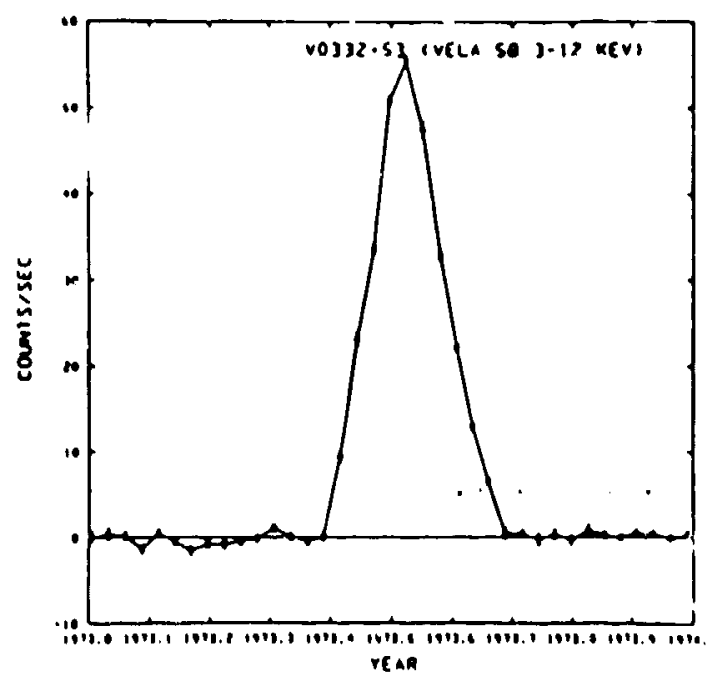

F18. 3. Time history of the 1973 translent outburat of v0332+53.

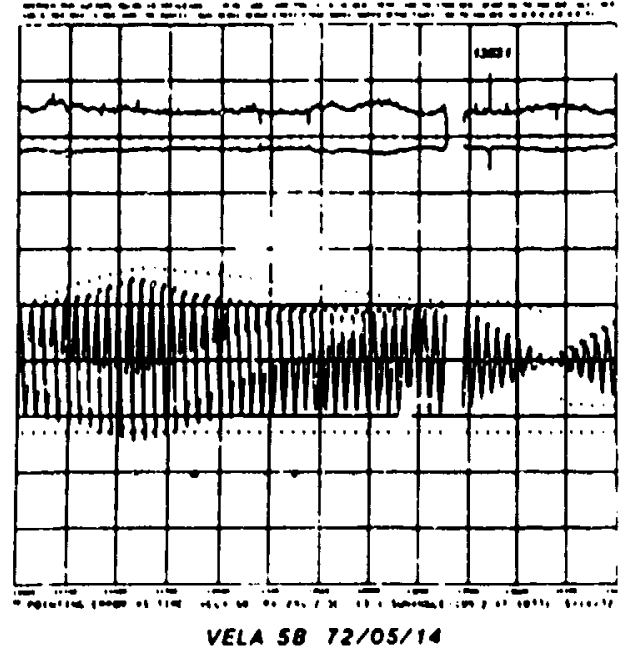

F1g. 4. Vela X-ray data showing detection of a gamma-ray burst.

of a number of rapld changes in intensity during this active period, often occurring in less than 10 days.1j Since the $X-r a y$ emission of ten reached the level of $5 \times 10^{42}$ ergs $\mathrm{sec}^{-1}$, the source of $X$ rays $1 \mathrm{~s}$ obvlously both small and massive.

Thus the 10-day akymaps produced from the vela 5B data have led to number of imfortant results. The full data are much more complete, with 2 energy channels, 1-second time resolution, and observations of Individual sources every 64 seconds. By means of this capability Vela $5 A$ and $5 B$ recorded brief uutbursts from a number of $X-r a y$ gources, leading to the discovery of the phenomenon of $X$-ray bursts. $2,3,5$ Th1s was also found independentlyl $b$ from observations by the Astronomical Netherlands Satellite.

A complete re-examination of the Vela $X-r a y$ burst data has recently been undertaken. The use of more atringent criterla for acceptance of burst data, such as requiring that the birst appear convincingly in both energy channels and that the data be free of charged-particle effects, has eliminated most of the large number of possible bursts observed.17 The convincing bursta are mostly from known sources, and particularly from 4U1608-52, the Norma burst source. A number of large burgts not prevlously reported have been found to come from this source, which 18 evidently one of the nearest burst sources, or at least one of the most intense observed.

A few large bursts per year do not come from known burst nources. Some of these are likely to be the X-rays assoclated with gamma-ray bursts. Two of these $X-r a y$ bursts have been 1dentifled with known gamma-ray burati, 4 one (GB720514) at galact1c coordinatea $l=129^{\circ}, b=39^{\circ}$, and the other (GB740723) from an area nenr the Small Magelianic Cloud (the direction of this burst 1 s known only from the $X-r a y$ duta). Th1s 1 a about the numbir of such detections expected, considering the viewing area of the Vela collimator and the fraction of timn devoted to data acquisition from the spacecraft. Tha counting rate of the vela $x-r a y$ counter during one of these Ramma-ray burnt detections (6.6720514) 1a shown in Figure 4, which 
Includes one hour of observation. The 4-second average of ccunting rates is shown near the top of the figure, with the total counting rate from both channels plotted in the positive sense, and the counting rate from the 6-12 keV channel plotted negatively, from the same IIne. Other spacecraft data shown Indicate nornal operation. The very obvious hard peak at 13631 UT ( $t$ ime recelve" is similar to many other $X-r a y$ bursts, but comes from the direction and at the time of a known ganma-ray burst. There are sloo indications of weaker recurrences of $X$ rays from the same source. 4

Thus the Vela X-ray data have proved to be important in the discovery of bursts, transients, and periodicities, Indicating the value of all-sky monitoring capablilty over an extended perlod of time, even with detectors of less than Ideal sensitivity. This work was supporied by the U.S. Department of Energy and by the Department of Defense.

\section{REFERENCES}

1. J. P. Conner, W. D. Evans, and R. D. Bel1an, Ap. J. 157, L157 (1969).

2. R. D. Bellan, J. P. Conner, and W. D. Evans, Ap. J. 206, L135 (1976).

3. W. D. Evans, R. D. Reliun, and J. P. Conner, Ap. J. 207, L91 (1976).

4. J. Terre11, E. E. Fenlmore, R. W. Klebesadel, arid U. D. Desa1, Ap. J. 254, 279 (1282); erratum, Ap. J. 269, 806 (1983).

5. R. D. Bollan, J. P. Conner, and W. D. Evans, Ap. J. 171, L87 (1972).

6. C. R. Canizares, J. E. McClintock, and J. E. Grindlay, Ap. J. 236, I.55 (1980).

7. J. Terrell, R. D. Bellan, J. P. Conner, and W. D. Evans, Bull. A.P.S. 24, 583 (1979).

B. J. Terre11, P.. D. Bellan, J. P. Conner, '.. D. Evans, and W. C. Prledtiorsky, Bull. A,A.S. 14,619 (1982). Prints of the movie "The X-Ray Sky, 1969-1976" are now avallable.

9. J. Terre1' W. C. Prledhorsky, R. D. Bellan, J. P. Conner, and W. D. Eva 1, pp. 210-212 in Accreting Neutron Stars (W. Brin' ann and J. Trlimper, editors; Max-Planck-Institut fur Extrater strische Physik, Garching bel Munchen, 1982).

10. H. C. C Ilan, Sky o Telescope 65, 494 (1983); flgure supplied by $\mathrm{J}$. ' reli.

11. W. C. "ledhorsky, J. Terrell, and S. S. Ho1t, Ap. I. 270, 233 (1983 .

12. W. C. 'rledhorsky and J. Terre11, Nature 303, 681 (1983).

13. W. (: Prledhoraky and J. Terre11, Ap. J., In press (1933).

14. J. H Beall et al., Ap. J. 219,836 (1978).

15. J.' rel1, pp. $117-118$ In Extragalactic Rad10 Sources (D. Heeschen and C. M. Wade, editors; IAU Sympos1um No. 97 ; D. Reldel Publishing Co., Dordrecht, 1982).

16. J. Cit Indlay et al., Ap. J. 205, I.127 (1976).

17. R. D. BnlLan, J. P. Conner, and W. D. Evans, Ap. J. 207, L33 (1976). 